\title{
Are Platelet Indices such as Platelet Volume, Platelet Distribution Width, and Plateletcrit Associated with Peyronie Disease?
}

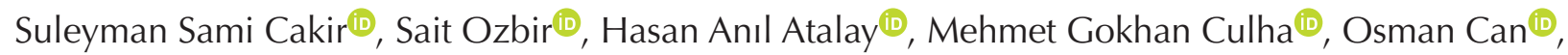 \\ Halil Lütfi Canat ${ }^{(\mathbb{0}}$ \\ Department of Urology, Okmeydani Training and Research Hospital, Istanbul, Turkey
}

Purpose: Peyronie disease (PD) occurs as a result of recurrent microvascular injuries or trauma of the tunica albuginea, although its precise etiology is unknown. Mean platelet volume (MPV), platelet distribution width (PDW), and plateletcrit (PCT), which are parameters indicative of platelet activity, are considered to be functional markers of platelets involved in the pathophysiology of related inflammatory and vascular diseases. In this study, we aimed to examine the relationship between PD and platelet indices.

Materials and Methods: We evaluated participants who presented to the andrology department of our institution between December 2015 and May 2018. Ninety-two men with PD and 80 healthy volunteers were included in this study. Participants who had received medical treatment affecting platelets or had any hematologic or systemic diseases were excluded from the study.

Results: The mean age of men with PD was $53.8 \pm 10.2$ years, and the mean age of the control group was $52.2 \pm 8.0$ years $(p=0.465)$. There were no significant differences in the mean IIEF-5 scores, platelet count, MPV, PDW, or PCT between the patients with and without PD $(\mathrm{p}<0.05)$.

Conclusions: No correlations were found between PD and platelet indices. Large-scale prospective cross-sectional studies are needed to elucidate the etiopathogenesis of PD.

Keywords: Mean platelet volume; Peyronie disease; Platelet distribution width; Plateletcrit

This is an Open Access article distributed under the terms of the Creative Commons Attribution Non-Commercial License (http://creativecommons.org/licenses/by-nc/4.0) which permits unrestricted non-commercial use, distribution, and reproduction in any medium, provided the original work is properly cited.

\section{INTRODUCTION}

Peyronie disease (PD), which is defined by the formation of fibrous plaque in the tunica albuginea, a layer of the penis, is a connective tissue disease. The prevalence of PD is reported to be $0.4 \%$ to $9.0 \%[1,2]$. Al- though PD is mostly seen in men aged 55 to 60 years, it can also occur in young males. However, a large proportion of patients have not yet been diagnosed [3].

The exact cause of PD is unknown, but repetitive microvascular trauma of the tunica albuginea is one of the most important hypotheses [4]. Following trauma,

Received: Mar 11, 2019 Revised: May 4, 2019 Accepted: May 9, 2019 Published online Jun 26, 2019

Correspondence to: Suleyman Sami Cakir (iD https://orcid.org/0000-0002-0211-3450

Department of Urology, Okmeydani Training and Research Hospital, Kaptan Paşa Mahallesi, Darülaceze Cad. No:25, 34384 Okmeydani, Sisli, Istanbul, Turkey.

Tel: +90-212-314-5500, Fax: +90-212-314-5503, E-mail: ssamicakir@hotmail.com 
fibrin and platelets accumulate between the layers of the penis due to extravasation [5]. Fibrin acts as a potent chemotactic factor that attracts inflammatory cells such as neutrophils, granulocytes, macrophages, and mast cells [6]. These inflammatory cells and platelets release various proinflammatory cytokines, of which transforming growth factor beta-1 (TGF- $\beta 1$ ) and platelet-derived growth factor (PDGF) are the most important [7]. The inflammatory response that occurs in response to recurrent trauma affects connective tissue and leads to fibrotic changes in the tunica albuginea $[8,9]$.

PDGF is primarily produced by platelets, but is also produced by macrophages. Just like TGF- $\beta 1$, PDGF also plays a chemotactic role for fibroblasts [10]. Intercalarily, PDGF induces fibroblast proliferation and differentiation to myofibroblasts, collagen biosynthesis, and the tissue inhibitors of matrix metalloproteinase synthesis, in addition to contributing to plaque calcification and ossification [11-14].

There are two phases of PD [15]. The first is the acute inflammatory stage, which may cause painful erections and may be associated with a palpable plaque in the tunica layer of the penis. The development of penile curvature at this stage is typical. The second is the chronic phase, characterized by hard, calcified penile plaque formation. At this stage, curvature formation and disease progression are stabilized [16].

Mean platelet volume (MPV), platelet distribution width (PDW), and plateletcrit (PCT), which reflect platelet activity, are considered to be functional markers of platelet involvement in the pathophysiology of related diseases. Several studies have shown that MPV is associated with vascular diseases and systemic diseases that cause vascular disorders, such as diabetes mellitus, sepsis, and cardiac infarction [17-19]. However, there are few studies in the literature related to PCT and PDW. Considering the role of platelets in the abovementioned inflammatory processes, we hypothesized that changes in MPV, PDW, and PCT values in acute PD, which are typical responses to inflammation, may be important for predicting the disease and to some extent, for obtaining further insights into its etiology. Moreover, we hypothesized that platelet markers may help distinguish whether the disease has stabilized.

\section{MATERIALS AND METHODS}

\section{Ethics statement}

The present study protocol was reviewed and approved by the Institutional Review Board of Okmeydan Traning and Research Hospital (Reg. No. 48670771514.10). Informed consent was submitted by all subjects when they were enrolled.

\section{Subject}

Ninety-two patients with acute-phase PD with no history of any infectious diseases in the prior 3 months admitted to the andrology outpatient clinic and 80 healthy volunteers recruited between December 2015 and May 2018 participated in the study. The diagnosis of PD was confirmed by color Doppler ultrasonography by a single radiologist after a manual examination of penile plaque. The acute phase was defined by the duration of the disease ( $<18$ months) or the presence of a painful erection. The degree of penile curvature and penile deformity were assessed by an intracavernous injection using papaverine. Patients' erectile function and pain were evaluated using the validated International Index of Erectile Function-5 items (IIEF-5) questionnaire [20] and a visual analogue scale (VAS), respectively. The IIEF-5 scores ranged from 5 to 25 points, and scores $<17$ were defined as erectile dysfunction (ED). On the VAS, a score of 0 indicated painless erections.

Patients were not included in the study if they had cardiovascular, hepatic, pulmonary, renal, or other systemic diseases (e.g., metabolic syndrome, thyroid function disorders, infections, cancer, smoking, other connective tissue disorders). Patients who received drug therapy or any other medical treatment for PD were also excluded from the study.

The complete blood cell count, platelet count, MPV, PDW, and PCT were measured in a single laboratory using an automated hematology analyzer (Sysmex XN1000 hematology analyzer; Sysmex Corporation, Kobe, Japan). All blood samples were placed into tubes coated with ethylenediaminetetraacetic acid. After the blood samples were taken, measurements were performed within 2 hours, which is the optimal interval [21].

\section{Statistical analysis}

The two-sample t-test or the Mann-Whitney U-test was used to compare the baseline characteristics of the 
groups. The Fisher exact test and Pearson chi-square test were used to analyze categorical data. The Kruskal-Wallis test was used to compare three or more groups. A p-value $<0.05$ was considered to indicate statistical significance. All analyses were conducted using SPSS ver. 15.0 (SPSS Inc., Chicago, IL, USA).

Table 1. Demographic and clinical characteristics of the groups

\begin{tabular}{lccc}
\hline \multicolumn{1}{c}{ Variable } & $\begin{array}{c}\text { Patients with } \\
\text { Peyronie disease } \\
(\mathbf{n = 9 2 )}\end{array}$ & $\begin{array}{c}\text { Patients without } \\
\text { Peyronie disease } \\
(\mathbf{n = 8 0})\end{array}$ & \\
\hline Age $(\mathrm{y})$ & $53.8 \pm 10.2$ & $52.2 \pm 8.0$ & 0.465 \\
$\mathrm{BMI}\left(\mathrm{kg} / \mathrm{m}^{2}\right)$ & $27.4 \pm 3.7$ & $27.6 \pm 4.0$ & 0.593 \\
Testosterone $(\mathrm{ng} / \mathrm{mL})$ & $3.9 \pm 1.1$ & $4.2 \pm 1.5$ & 0.198 \\
CRP $(\mathrm{mg} / \mathrm{dL})$ & $0.21 \pm 0.23$ & $0.23 \pm 0.34$ & 0.256 \\
IIEF-5 score & $19.6 \pm 3.9$ & $20.2 \pm 5.5$ & 0.313 \\
Disease duration $(\mathrm{mo})$ & $10.3 \pm 5.3(1-18)$ & & \\
Degree of curvature $\left({ }^{\circ}\right)$ & $27.2 \pm 15.1(0-45)$ & & \\
Painful erections & $57(61.9)$ & & \\
Plaque size (mm) & $13.3 \pm 8.8(2-49)$ & & \\
\hline
\end{tabular}

Values are presented as mean \pm standard deviation only, mean \pm standard deviation (range), or number (\%).

BMI: body mass index, CRP: C-reactive protein, IIEF-5: International Index of Erectile Function-5 items.

at-test/Mann-Whitney U-test/chi-square test.

\section{RESULTS}

All patients with PD were in the acute phase, and 57 of these patients $(61.9 \%)$ had painful erections. The mean plaque size measured by color Doppler ultrasonography in PD patients was $13.3 \pm 8.8 \mathrm{~mm}$ (range, $2-49$ $\mathrm{mm})$. No differences were observed between the two groups in terms of age, body mass index, C-reactive protein levels, IIEF-5 scores, or testosterone levels ( $>0.05$ ). The presence of PD was the only meaningful difference between the two groups. The clinical and demographic features of the two groups are shown in Table 1.

There were no significant differences in the platelet

Table 2. The platelet count and platelet indices according to group

\begin{tabular}{lccc}
\hline Variable & $\begin{array}{c}\text { Patients with } \\
\text { Peyronie disease }\end{array}$ & $\begin{array}{c}\text { Patients without } \\
\text { Peyronie disease }\end{array}$ & p-value $^{\mathrm{a}}$ \\
\hline PLT $(\mathrm{n} / \mu \mathrm{L})$ & $251.1 \pm 58.6$ & $235.9 \pm 55.3$ & 0.078 \\
PDW $(\mathrm{fL})$ & $16.8(8.3-24.1)$ & $17.1(9.9-22.5)$ & 0.243 \\
PCT $(\%)$ & $0.20(0.13-0.41)$ & $0.21(0.10-0.33)$ & 0.762 \\
MPV (fL) & $9.7 \pm 1.0$ & $9.3 \pm 1.1$ & 0.163 \\
\hline
\end{tabular}

Values are presented as mean \pm standard deviation or median (range). PLT: platelet, PDW: platelet distribution width, PCT: plateletcrit, MPV: mean platelet volume.

${ }^{a}$ Mann-Whitney U-test.

Table 3. Platelet count and platelet indices according to the duration of disease

\begin{tabular}{|c|c|c|c|c|c|c|}
\hline \multirow{2}{*}{ Variable } & \multicolumn{4}{|c|}{ Duration of disease } & \multirow{2}{*}{ Control $(n=80)$} & \multirow{2}{*}{$p$-value ${ }^{a}$} \\
\hline & $0-3 \mathrm{mo}(\mathrm{n}=30)$ & $3-6 \mathrm{mo}(\mathrm{n}=27)$ & $6-12 \mathrm{mo}(\mathrm{n}=19)$ & $>12 \mathrm{mo}(\mathrm{n}=16)$ & & \\
\hline $\mathrm{PLT}(\mathrm{n} / \mu \mathrm{L})$ & $251.1 \pm 58.6$ & $235.9 \pm 55.3$ & $241.4 \pm 59.3$ & $239.5 \pm 47.6$ & $235.9 \pm 55.3$ & 0.475 \\
\hline PDW (fL) & $15.6(7.3-25.1)$ & $16.1(8.9-23.5)$ & $17.1(8.3-24.1)$ & $16.2(6.9-19.2)$ & $17.1(9.9-22.5)$ & 0.343 \\
\hline РCT (\%) & $0.19(0.11-0.35)$ & $0.21(0.14-0.36)$ & $0.18(0.15-0.41)$ & $0.20(0.12-0.43)$ & $0.21(0.10-0.33)$ & 0.612 \\
\hline MPV (fL) & $9.5 \pm 1.1$ & $9.8 \pm 1.7$ & $9.4 \pm 1.0$ & $9.9 \pm 1.6$ & $9.3 \pm 1.1$ & 0.593 \\
\hline
\end{tabular}

Values are presented as mean \pm standard deviation or median (range).

PLT: platelet, PDW: platelet distribution width, PCT: plateletcrit, MPV: mean platelet volume.

${ }^{a}$ Kruskal-Wallis test.

Table 4. Platelet count and platelet indices according to curvature degree

\begin{tabular}{lcccc}
\hline \multirow{2}{*}{ Variable } & \multicolumn{2}{c}{ Curvature degree } & Control $(\mathrm{n}=\mathbf{8 0})$ & $\mathrm{p}$-value \\
\cline { 2 - 4 } & $<30^{\circ}(\mathrm{n}=31)$ & $\geq 30^{\circ}(\mathrm{n}=61)$ & $235.9 \pm 55.3$ & 0.183 \\
PLT $(\mathrm{n} / \mu \mathrm{L})$ & $241.3 \pm 57.6$ & $239.8 \pm 56.7$ & $17.1(9.9-22.5)$ & 0.342 \\
PDW (fL) & $19.8(9.3-25.1)$ & $18.6(8.9-21.5)$ & $0.21(0.10-0.33)$ & 0.652 \\
PCT (\%) & $0.19(0.12-0.39)$ & $0.20(0.13-0.35)$ & $9.3 \pm 1.1$ & 0.463 \\
MPV (fL) & $9.3 \pm 2.0$ & $9.1 \pm 1.5$ & \\
\hline
\end{tabular}

Values are presented as mean \pm standard deviation or median (range).

PLT: platelet, PDW: platelet distribution width, PCT: plateletcrit, MPV: mean platelet volume.

${ }^{a}$ Kruskal-Wallis test. 
count, MPV, PDW, or PCT between the two groups (patients vs. control) ( $p>0.05$, Table 2). When the patients were grouped according to disease duration, no statistically significant differences were observed ( $>0.05$ ) (Table 3). Furthermore, there were no significant differences in patients' platelet indices depending on whether the degree of penile curvature was $<30^{\circ}$ or $\geq 30^{\circ}$ ( $\left.p>0.05\right)$ (Table 4). Finally, there were no statistically significant differences in the platelet indices between patients with and without painful erections $(p>0.05)$.

\section{DISCUSSION}

Platelets and related markers have been reported to function as biomarkers of vascular injury and inflammation in many studies [22,23]. Among these platelet indices, considerably more studies have investigated MPV than have investigated PDW and PCT. Furthermore, no study has yet explored the relationship between PD and platelet indices. Therefore, to our knowledge, our study is the first to investigate the relationship between PD and platelet indices (MPV, PDW, and PCT) in the literature.

Although MPV and other platelet indices have been reported to be predictive markers in vascular pathologies and inflammatory disorders in most studies, opposing views have also been presented in the literature. Çoban et al [24] compared patients with varicocele to healthy individuals and found that MPV values were significantly higher in patients with varicocele, while platelet count and PDW values were significantly lower. In contrast, Polat et al [25] found no correlation between the presence of varicocele and platelet count or platelet indices. The authors stated that varicocele is a venous disease, not an arterial disease. Since MPV is usually associated with arterial diseases, a pathological relationship may not exist between platelet indices and varicocele. In addition, some reports have suggested that the MPV and PDW indices do not reflect platelet function, and that the gold-standard method for assessing platelet function is platelet aggregation [26]. Similarly, Beyan et al [27] did not find a correlation between platelet indices and platelet aggregation responses in healthy subjects. In our study, we expected that the values of platelet indices would be different between PD patients and healthy individuals if platelet indices had predictive value for vascular diseases and the inflammatory process, because the acute phase of PD is an active inflammatory process due to microvascular trauma. The recent study of De Rose et al [28] also supports this theory of microvascular trauma in PD. They demonstrated similar characteristics between post-trauma plaques and PD plaques using electronic microscopy. In all the samples they analyzed, they observed an inflammatory reaction of the structure of the tunica albuginea, disorganization of the extracellular matrix, and a proliferation of inflammatory cells and fibroblasts. Trauma also leads to increased levels of TGF- $\beta 1$, which is abundant in platelets. Lindholm et al [29] showed that TGF- $\beta 1$ mRNA significantly increased in rat brain cortices with lesions after a penetrating injury. In light of this information, recurrent microtraumas and a chronic inflammatory process could logically be expected to lead to changes in platelet indices. However, we did not observe any significant differences in platelet indices, including the platelet count, MPV, PDW, and PCT, between patients with PD and healthy individuals. This result may have resulted from the exclusion of patients with many systemic diseases in our study. The most common comorbidities and risk factors of $\mathrm{PD}$ are hypertension, dyslipidemia, cardiovascular disease, diabetes mellitus, ED, smoking, chronic alcohol consumption, and Dupuytren's contracture [2,16,30,31]. It is also known that MPV and other platelet indices are closely associated with these systemic diseases. Thus, according to our study, MPV, PDW, and PCT may not be independent risk factors or indicators of PD.

Another reason for the differences between published studies may be that the measurements were not standardized sufficiently. It is important that prospectively-planned studies about platelet indices standardize the anticoagulant type, measurement technology, and the measurement time after venipuncture to ensure data accuracy and reliability [32].

The main limitation of this manuscript is that this study excluded patients with many systemic diseases, including the most common comorbidities and risk factors that could affect PD progression. Because of these exclusion criteria, the platelet indices of the participants did not show clear differences between patients with PD and healthy volunteers. However, not all PD patients may have an associated systemic disease as a comorbidity. In this respect, we believe that the results of the study are noteworthy despite its limitations. 


\section{CONCLUSIONS}

We did not find any significant relationship between PD and platelet indices when we excluded all risk factors in our study. There is a need for larger case series and cross-sectional studies.

\section{Conflict of Interest}

The authors have nothing to disclose.

\section{Author Contribution}

Conceptualization: SSC, HLC. Data curation: SSC, OC. Formal analysis: HAA, SO. Funding acquisition: HAA, SO. Investigation: SSC, MGC. Methodology: SO, HAA. Project administration: MGC, HAA. Resources: SSC, OC. Software: SO, SSC. Supervision: SSC, HAA. Validation: MGC, SSC, Visualization: SO, SSC. Writing-original draft: SSC, HLC. Writing-review \& editing: SSC, HLC.

\section{Data Sharing Statement}

The data required to reproduce these findings cannot be shared at this time as the data also forms part of an ongoing study.

\section{REFERENCES}

1. Mulhall JP, Creech SD, Boorjian SA, Ghaly S, Kim ED, Moty A, et al. Subjective and objective analysis of the prevalence of Peyronie's disease in a population of men presenting for prostate cancer screening. J Urol 2004;171:2350-3.

2. Lindsay MB, Schain DM, Grambsch P, Benson RC, Beard CM, Kurland LT. The incidence of Peyronie's disease in Rochester, Minnesota, 1950 through 1984. J Urol 1991;146:1007-9.

3. Stuntz M, Perlaky A, des Vignes F, Kyriakides T, Glass D. The prevalence of Peyronie's disease in the United States: a population-based study. PLoS One 2016;11:e0150157.

4. Devine CJ Jr, Somers KD, Jordan SG, Schlossberg SM. Proposal: trauma as the cause of the Peyronie's lesion. J Urol 1997;157:285-90.

5. Paulis G, Romano G, Paulis L, Barletta D. Recent pathophysiological aspects of Peyronie's disease: role of free radicals, rationale, and therapeutic implications for antioxidant treatment-literature review. Adv Urol 2017;2017:4653512.

6. Somers KD, Dawson DM. Fibrin deposition in Peyronie's disease plaque. J Urol 1997;157:311-5.
7. Garaffa G, Trost LW, Serefoglu EC, Ralph D, Hellstrom WJ. Understanding the course of Peyronie's disease. Int J Clin Pract 2013;67:781-8.

8. Gonzalez-Cadavid NF, Rajfer J. Mechanisms of disease: new insights into the cellular and molecular pathology of Peyronie's disease. Nat Clin Pract Urol 2005;2:291-7.

9. Jarow JP, Lowe FC. Penile trauma: an etiologic factor in Peyronie's disease and erectile dysfunction. J Urol 1997;158:138890.

10. Andrae J, Gallini R, Betsholtz C. Role of platelet-derived growth factors in physiology and medicine. Genes Dev 2008; 22:1276-312.

11. El-Sakka AI, Salabas E, Dinçer M, Kadioglu A. The pathophysiology of Peyronie's disease. Arab J Urol 2013;11:272-7.

12. Gonzalez-Cadavid NF, Magee TR, Ferrini M, Qian A, Vernet D, Rajfer J. Gene expression in Peyronie's disease. Int J Impot Res 2002;14:361-74.

13. Moreland RB, Nehra A. Pathophysiology of Peyronie's disease. Int J Impot Res 2002;14:406-10.

14. Lambert E, Dassé E, Haye B, Petitfrère E. TIMPs as multifacial proteins. Crit Rev Oncol Hematol 2004;49:187-98.

15. Ralph D, Gonzalez-Cadavid N, Mirone V, Perovic S, Sohn M, Usta M, et al. The management of Peyronie's disease: evidence-based 2010 guidelines. J Sex Med 2010;7:2359-74.

16. Kadioglu A, Tefekli A, Erol B, Oktar T, Tunc M, Tellaloglu S. A retrospective review of 307 men with Peyronie's disease. J Urol 2002;168:1075-9.

17. Sopova K, Tatsidou P, Stellos K. Platelets and platelet interaction with progenitor cells in vascular homeostasis and inflammation. Curr Vasc Pharmacol 2012;10:555-62.

18. Amraotkar AR, Song DD, Otero D, Trainor PJ, Ismail I, Kothari V, et al. Platelet count and mean platelet volume at the time of and after acute myocardial infarction. Clin Appl Thromb Hemost 2017;23:1052-9.

19. Shah B, Valdes V, Nardi MA, Hu L, Schrem E, Berger JS. Mean platelet volume reproducibility and association with platelet activity and anti-platelet therapy. Platelets 2014;25:188-92.

20. Rhoden EL, Telöken C, Sogari PR, Vargas Souto CA. The use of the simplified International Index of Erectile Function (IIEF-5) as a diagnostic tool to study the prevalence of erectile dysfunction. Int J Impot Res 2002;14:245-50.

21. Mahdavi-Zafarghandi R, Shakiba B, Keramati MR, Tavakkoli M. Platelet volume indices in patients with varicocele. Clin Exp Reprod Med 2014;41:92-5.

22. Gawaz M, Langer H, May AE. Platelets in inflammation and atherogenesis. J Clin Invest 2005;115:3378-84.

23. Balta S, Demir M, Demirkol S, Ozturk C, Celik T. Mean platelet volume in patients with varicocele. Andrologia 2015;47: 
365-6.

24. Çoban S, Keleş I, Biyik I, Güzelsoy M, Türkoğlu AR, Özgünay $\mathrm{T}$, et al. Is there any relationship between mean platelet volume and varicocele? Andrologia 2015;47:37-41.

25. Polat H, Gulpinar MT, Sarıca MA, Benlioglu C. Relationship between mean platelet volume, platelet distribution width, plateletcrit and varicocele. Andrologia 2017;49:e12594.

26. Beyan C, Beyan E. Mean platelet volume may not be related to the physiopathology of varicocele. Andrologia 2015;47:367.

27. Beyan C, Kaptan K, Ifran A. Platelet count, mean platelet volume, platelet distribution width, and plateletcrit do not correlate with optical platelet aggregation responses in healthy volunteers. J Thromb Thrombolysis 2006;22:161-4.

28. De Rose AF, Mantica G, Bocca B, Szpytko A, Van der Merwe A, Terrone C. Supporting the role of penile trauma and micro-trauma in the etiology of Peyronie's disease. Prospective observational study using the electronic microscope to examine two types of plaques. Aging Male 2019. doi: 10.1080/13685538.2019.1586870 [Epub].

29. Lindholm D, Castrén E, Kiefer R, Zafra F, Thoenen H. Transforming growth factor-beta 1 in the rat brain: increase after injury and inhibition of astrocyte proliferation. J Cell Biol 1992;117:395-400.

30. Sommer F, Schwarzer U, Wassmer G, Bloch W, Braun M, Klotz T, et al. Epidemiology of Peyronie's disease. Int J Impot Res 2002;14:379-83.

31. Rhoden EL, Riedner CE, Fuchs SC, Ribeiro EP, Halmenschlager G. A cross-sectional study for the analysis of clinical, sexual and laboratory conditions associated to Peyronie's disease. J Sex Med 2010;7:1529-37.

32. Beyan C, Beyan E. Were the measurements standardized sufficiently in published studies about mean platelet volume? Blood Coagul Fibrinolysis 2017;28:234-6. 